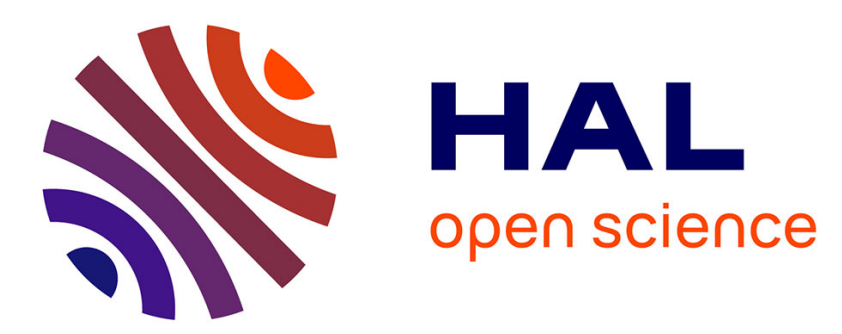

\title{
RFC1 gene intronic repeat expansion and unexplained chronic cough: A pathophysiological conundrum
}

\author{
M. Humbert, A. Echaniz-Laguna, Guillaume Fargeot
}

\section{To cite this version:}

M. Humbert, A. Echaniz-Laguna, Guillaume Fargeot. RFC1 gene intronic repeat expansion and unexplained chronic cough: A pathophysiological conundrum. Respiratory Medicine and Research, 2021, 80, pp.100831. 10.1016/j.resmer.2021.100831 . hal-03266483

\section{HAL Id: hal-03266483 \\ https://hal.sorbonne-universite.fr/hal-03266483}

Submitted on 21 Jun 2021

HAL is a multi-disciplinary open access archive for the deposit and dissemination of scientific research documents, whether they are published or not. The documents may come from teaching and research institutions in France or abroad, or from public or private research centers.
L'archive ouverte pluridisciplinaire HAL, est destinée au dépôt et à la diffusion de documents scientifiques de niveau recherche, publiés ou non, émanant des établissements d'enseignement et de recherche français ou étrangers, des laboratoires publics ou privés. 


\title{
$\underline{\text { Editorial }}$
}

\section{RFC1 gene intronic repeat expansion and unexplained chronic cough: a pathophysiological conundrum}

\author{
Guillaume FARGEOT $^{\mathrm{a}^{*}}$, Marc HUMBERT ${ }^{\mathrm{b}}$ \& Andoni ECHANIZ-LAGUNA ${ }^{\mathrm{c}, \mathrm{d}, \mathrm{e}}$
}

a. Neurophysiology Department, Assistance Publique Hôpitaux de Paris (AP-HP), PitiéSalpêtrière Hospital, Paris, France.

b. Université Paris-Saclay; Inserm U999; Service de Pneumologie et Soins Intensifs Respiratoires, Hôpital Bicêtre, AP-HP, Le Kremlin-Bicêtre, France.

c. Neurology Department, Assistance Publique Hôpitaux de Paris (AP-HP), CHU de Bicêtre, Le Kremlin-Bicêtre, France.

d. French National Reference Center for Rare Neuropathies (NNERF), Le Kremlin-Bicêtre, 94276, France.

e. INSERM U1195, Paris-Saclay University, Le Kremlin-Bicêtre, France.

\section{* Corresponding author:}

Guillaume Fargeot

Neurophysiology Department, Assistance Publique Hôpitaux de Paris (AP-HP), Pitié-

Salpêtrière Hospital, Boulevard de l'Hôpital, 75013 Paris, France.

Email: guillaume.fargeot@aphp.fr

T: +33142162133

Take home message: $R F C 1$ gene intronic expansions as a cause of isolated chronic cough.

Characteristics of the manuscript

Title: 97 characters (including spaces)

Text: 1121 words.

16 references 
Dear editor,

A 68-year-old woman was admitted to the Neurology department after complaining of distal lower limb paresthesia and gait impairment slowly aggravating for 10 years. She had no significant past medical history other than chronic cough since her 30 s, which had been extensively investigated by several pulmonologists and labelled unexplained chronic cough (UCC). Her cough was dry, with severe bursts provoked by strong olfactory stimuli -for instance, she could not tolerate entering a perfume shop. Cough was also provoked by tobacco smoke and mechanical stimulation of the external auditory meatus, ie. Arnold ear-cough reflex, for example with a cotton bud. Physical examination showed normal strength, preserved deep tendon reflexes, mild proprioceptive ataxia, positive Romberg sign, lower limbs hypoesthesia and a gaze-evoked nystagmus. Electrodiagnostic studies showed absent sensory nerve action potentials in all limbs and normal motor conduction velocities, consistent with sensory neuronopathy. Caloric studies showed vestibular areflexia and brain magnetic resonance imaging demonstrated mild cerebellum atrophy. The combination of sensory neuronopathy, chronic cough, cerebellar atrophy and vestibular areflexia prompted $R F C 1$ gene analysis, which demonstrated a $R F C 1$ abnormal biallelic expansion typical of Cerebellar Ataxia with Neuropathy and Vestibular Areflexia Syndrome (CANVAS).

CANVAS is a rare autosomal recessive neurological disorder caused by biallelic intronic pentanucleotide expansions in the RFCl gene involved in DNA repair.[1] Although CANVAS frequency is unknown, recent data suggests a prevalence of 1 in 20,000 homozygous carriers.[2] Mean disease onset is around the sixth decade. The disease has a slowly progressive course, and gait impairment related to cerebellar ataxia or sensory neuronopathy is usually the main symptom.[3] Half of the patients need walking aid ten years after disease onset, and $25 \%$ are wheelchair-dependent five years later.[1] CANVAS 
phenotypic spectrum is not yet completely defined, and parkinsonism and motor neuron involvement have been described in some cases. CANVAS clinically resembles neurohereditary disorders such as Friedreich's ataxia and $P O L G$ gene-related mitochondrial disorders, albeit CANVAS exact pathophysiology is yet unknown.[2]

Almost $60 \%$ of CANVAS patients present with chronic cough.[1] Ear, neck, throat, and pulmonary investigations are usually normal, and in most cases CANVAS patients are diagnosed with UCC.[4] CANVAS cough is a chronic spasmodic dry cough appearing in bursts, with variable frequency and severity, from occasional bursts throughout the year to daily bursts lasting several hours.[5] Of note, cough precedes neurological symptoms in most cases, with an interval that may be as long as three decades.[1-6] In a recent report, 35 out of 70 CANVAS patients had chronic cough.[6] Median age of cough onset was 35 years, and cough preceded gait ataxia in $80 \%$ of cases with a median interval of 16 years between cough onset and ataxia onset.[6] Triggering factors such as strong olfactory stimuli, external auditory meatus stimuli, upper airways stimuli (e.g. cold air), and esophagus stimuli (e.g. dry food) may induce cough.[5]

The mechanisms underlying cough in CANVAS, a neurological disorder affecting both peripheral and central nervous system, are debated. Cough is the result of a complex arc reflex initiated by the stimulation of larynx and tracheobronchial tree sensory nerve receptors that are mostly vagal in origin.[7] The afferent fibers are myelinated A $\delta$ fibers (mostly excitatory) and unmyelinated C fibers (excitatory or inhibitory) transmitting information from peripheral receptors mainly to solitary and trigeminal nuclei. The efferent pathways mainly originate from the retroambigualis and ambiguus nuclei and travel down the vagus, phrenic and spinal motor nerves to produce cough. Interestingly, CANVAS cough may result from dysfunction of the central and/or the peripheral nervous system. Many of CANVAS patients present with signs of cough hypersensitivity, i.e. allotussia and hypertussia.[8] Although 
debated, cough hypersensitivity may be provoked by denervation of the upper airways due to a laryngeal sensory neuropathy, as demonstrated by laryngeal electromyography.[9] The laryngeal sensory neuropathy could in turn cause peripheral and central cough reflex sensitization.[8-10] Many factors have been reported as a cause of laryngeal sensory nerves injury, i.e. infections, irritants, airway inflammation etc.[10] When considering CANVAS, laryngeal/vagus sensory neuropathy could be an early localization of a broader sensory neuronopathy. It is unknown why cough precedes neurological symptoms by decades, but a selective involvement of a subset of sensory fibers may be hypothesized. Interestingly, such a selective sensory fibers involvement has been demonstrated in CANVAS, with preservation of tendon reflexes despite deep sensory dysfunction, a clinical oddity seldom observed in patients with sensory neuronopathy.[5-11] The fact that some CANVAS patients present with Arnold ear-cough reflex is also an argument for a peripheral nervous system origin of cough, as sensory degeneration of the auricular branch of the vagus nerve is known to provoke cough.[12] In addition, vagus nerve involvement in CANVAS is likely as autonomic dysfunction is a major feature of this syndrome. Neurological central cough networks may also be involved in CANVAS. Indeed, it has been shown that vagal airway nociceptive inputs to the brainstem are regulated by a central descending suppressive control system.[13] Also, brain magnetic resonance imaging has shown neural activation patterns in cerebellum and brainstem in voluntary cough of healthy individuals.[10] As brainstem and cerebellum functions are impaired in CANVAS, including in neurologically asymptomatic patients, an early impairment of central networks of cough may be hypothesized.[13-14]

Chronic cough is a common medical problem, with a $10 \%$ prevalence in the general adult population.[15] Tobacco use, angiotensin-converting enzyme inhibitors, reflux and esophageal dysmotility, asthma, chronic respiratory diseases and rhinosinusitis are major causes of chronic cough.[15] The European Respiratory Society has recently developed 
guidelines for the diagnosis of chronic cough, and has underscored that initial evaluation should include spirometry and a recent chest radiography as first-line investigations.[15] In absence of symptoms and signs of specific disease, further investigations for asthma, eosinophilic bronchitis, reflux and oesophageal dysmotility and rhinosinusitis should be considered, depending on the clinical history.[15] This guideline also suggest a short-term inhaled corticosteroids trial in adults patients with chronic cough.[15] However, despite extensive work-up, a substantial proportion of patients (ranging from 7 to $40 \%$ ) are diagnosed with UCC.[10] The European Respiratory Society underlined in its last task force report that genetic studies are clinically useful in cough associated with neurological syndromes.[16] However, the proportion of patients with UCC who might have RFC1 gene mutations is currently unknown and the cost of RFC1 gene analysis in a common disease such as UCC remains to be evaluated. In this context, prospective studies to evaluate the prevalence, incidence and outcome of patients with UCC and RFCl gene repeat expansions would be of major interest after careful ethical consideration. Interestingly, a clinical trial investigating this point is underway (https://clinicaltrials.gov/ct2/show/NCT04703595).

Our report aims at improving awareness of a rare neurological cause of chronic cough and underscores the need for careful multidisciplinary evaluation of such cases, including pulmonologists, neurologists and geneticists. The interest of RFCl gene analysis in that context needs to be evaluated. 
1. Cortese A, Tozza S, Yau WY, et al. Cerebellar ataxia, neuropathy, vestibular areflexia syndrome due to RFC1 repeat expansion. Brain. 2020;143(2):489-90.

2. Cortese A, Simone R, Sullivan R, et al. Biallelic expansion of an intronic repeat in RFC1 is a common cause of late-onset ataxia. Nat Genet [Internet]. 2019;51(4):64958.

3. Montaut S, Diedhiou N, Fahrer P, et al. Biallelic RFC1-expansion in a French multicentric sporadic ataxia cohort. J Neurol [Internet]. 2021;(0123456789).

4. McGarvey L, Gibson PG. What Is Chronic Cough? Terminology. J Allergy Clin Immunol Pract [Internet]. 2019;7(6):1711-4.

5. Infante J, García A, Serrano-Cárdenas KM, et al. Cerebellar ataxia, neuropathy, vestibular areflexia syndrome (CANVAS) with chronic cough and preserved muscle stretch reflexes: evidence for selective sparing of afferent Ia fibres. J Neurol [Internet]. 2018;265(6):1454-62.

6. Traschütz A, Cortese A, Reich S, et al. Natural History, Phenotypic Spectrum, and Discriminative Features of Multisystemic RFC1-disease. Vol. 0, Neurology. 2021. 10.1212/WNL.0000000000011528.

7. Fuller RW, Jackson DM. Physiology and treatment of cough Cough. Thorax. $1990 ; 45: 425-30$.

8. Vertigan AE, Gibson PG. Chronic refractory cough as a sensory neuropathy: Evidence from a reinterpretation of cough triggers. $J$ Voice [Internet]. 2011;25(5):596-601.

9. Lee JK, Mintz S. Chronic cough as a sign of laryngeal sensory neuropathy: diagnosis and treatment. Ann Otol Rhinol Laryngol. 2006;115(11):871.

10. Chung KF, McGarvey L, Mazzone SS. Chronic cough as a neuropathic disorder. Lancet Respir Med. 2013;1(5):414-22.

11. Fargeot G, Echaniz-Laguna A. Sensory neuronopathies: new genes, new antibodies and 
new concepts. J Neurol Neurosurg Psychiatry. 2021;92:398-406.

12. Ryan NM, Gibson PG, Birring SS. Arnold's nerve cough reflex: Evidence for chronic cough as a sensory vagal neuropathy. J Thorac Dis. 2014;6:S748-52.

13. Mazzone SB, Bautista TG, Verberne AJM, et al. Descending modulation of laryngeal vagal sensory processing in the brainstem orchestrated by the submedius thalamic nucleus. J Neurosci. 2020;40(49):9426-39.

14. Dupré M, Hermann R, Froment Tilikete C. Update on Cerebellar Ataxia with Neuropathy and Bilateral Vestibular Areflexia Syndrome (CANVAS). Cerebellum. 2020 Oct;

15. Morice AH, Millqvist E, Bieksiene K, et al. ERS guidelines on the diagnosis and treatment of chronic cough in adults and children. Eur Respir J [Internet]. 2020;55(1).

16. Morice AH, Millqvist E, Belvisi MG, et al. Expert opinion on the cough hypersensitivity syndrome in respiratory medicine. Eur Respir J. 2014;44(5):1132-48. 